\title{
Effects of job demands and social interactions on fatigue in short sea cargo shipping
}

\author{
BIRGIT PAUKSZTAT \\ Forthcoming in Maritime Policy \& Management, published online on 6 March 2017, \\ available at http://dx.doi.org/10.1080/03088839.2017.1298868
}

\begin{abstract}
Although fatigue is considered an important problem in shipping, little is known about potential mitigating factors or resources for coping. Adopting a Job Demands-Resources (JD-R) framework, this paper examines the effects of both job demands (stressors) and resources on fatigue, focusing on social interactions on board as a potential source of social support. Using an incomplete repeated-measures design, the study combined information from documents with surveys on seven cargo ships. Findings indicated that fatigue levels were highest for those working on deck and for individuals at higher hierarchical levels. Higher numbers of port calls (and to some extent lower numbers of days at sea) also increased fatigue levels. By contrast, night watches and the number of days in port had no effect on fatigue. Supportive social interactions reduced fatigue (main effect), but their effect was weaker when the number of port calls increased (interaction effect). All main effects were mediated by individuals' perceptions of work pressure. Taken together, findings highlight the importance of considering social interactions on board to advance our understanding of stressors and strain in seafaring.
\end{abstract}

\section{Keywords}

Job Demands-Resources (JD-R) model; longer term fatigue; ship's schedule; short sea shipping; social support; watch keeping

\section{Affiliation and contact details}

Department of Human Resources and Organisational Behaviour, Business School, University of Greenwich, Queen Anne 106, Old Royal Naval College, Park Row, London SE10 9LS, United Kingdom. Telephone: +44 (0) 208331 9896. E-mail: B.Pauksztat@ greenwich.ac.uk 


\section{Introduction}

In research on seafaring, much effort has been devoted to better understand the psychological and physiological strains experienced by seafarers, and the stressors causing them (Bloor, Thomas, and Lane 2000; Oldenburg, Hogan, and Jensen 2013; Poulsen et al. 2014; Smith, Allen, and Wadsworth 2006). One kind of strain, fatigue, has received particular attention. Defined as 'a biological drive for recuperative rest' (Williamson et al. 2011, 499), fatigue 'may take several forms including sleepiness as well as mental, physical and/or muscular fatigue depending on the nature of its cause' (Williamson et al. 2011, 499). Symptoms can be cognitive (e.g., concentration or memory problems), emotional (e.g., irritability, depression), and/or physical (e.g., muscular pain, gastrointestinal problems) (Ganster and Rosen 2013; Glise et al. 2010; Sasaki et al. 2007). Previous studies have considered both acute and longer term fatigue (Wadsworth et al. 2008). Here, the focus will be on longer term fatigue, i.e. fatigue during the previous week.

Fatigue has been considered 'a main psychosocial problem in the shipping industry' (Oldenburg, Hogan, and Jensen 2013, 1). It does not only come with high personal costs for seafarers with regard to health and well-being (Oldenburg, Hogan, and Jensen 2013; Poulsen et al. 2014). It has also been listed among the 'human factors' that contribute to errors and accidents at sea, affecting the safety of vessels and crew (Akhtar and Utne 2015; Macrae 2009), with substantial financial implications for the shipping industry (Allianz Global Corporate \& Specialty 2015).

Not surprisingly, there has been much research on the antecedents of fatigue. This showed that fatigue is affected by workload as well as by work and rest hours (Oldenburg, Hogan, and Jensen 2013; Österman and Hult 2016; Smith, Allen, and Wadsworth 2006; Uğurlu 2016; Wadsworth et al. 2008). However, whereas research on seafaring has focused on stressors, theoretical and empirical work in other contexts suggests that mitigating factors or resources for coping should be considered as well.

According to the Job Demands-Resources (JD-R) model (Demerouti et al. 2001; for reviews, see Bakker, Demerouti, and Sanz-Vergel 2014; Ganster and Rosen 2013), the level of strain experienced by employees is affected by job demands and resources. Job demands are 'those physical, social, or organizational aspects of the job that require sustained physical or mental effort and are therefore associated with certain physiological and psychological costs (e.g., exhaustion)' (Demerouti et al. 2001, 501). Examples of job demands are workload, time pressure, shift work, and characteristics of the physical environment. Job resources are 'those physical, psychological, social, or organizational aspects of the job that may do any of the following: (a) be functional in achieving work goals; (b) reduce job demands at the associated physiological and psychological costs; (c) stimulate personal growth and development' (Demerouti et al. 2001, 501). Resources can include feedback and rewards, job control, and support from supervisors and colleagues. Here, the focus will be on the quality of social interactions with other crew members as a potential source of social support.

In seafaring, social interactions with colleagues have mostly received attention in qualitative research. Although few studies directly examined their effects on strain, research suggests that the quality of social interactions on board can affect collaboration and well-being (Knudsen 2004; Sampson and Thomas 2003). Surveys found significant effects of social support on seafarers' general health and fatigue (Rydstedt and Lundh 2010; Wadsworth et al. 2008), although, as noted by the authors, these findings should be interpreted with caution given the cross-sectional design, self-report data and the potential for common method bias (Podsakoff et al. 2003).

On the other hand, high workloads and limited leisure time may restrict the opportunities for socializing, leading to feelings of loneliness and isolation (Kahveci 1999; Knudsen 2004; Sampson and Thomas 2003). Recent developments in the industry, such as faster port turnaround times (Kahveci 1999), cost reductions and lower manning levels (Akhtar 2014; Allianz Global Corporate \& Specialty 2015; Fenstad, Dahl, and Kongsvik, 2016), and increasing bureaucracy (Österman and Hult 2016), may exacerbate the problem. Taken together, existing research 
suggests that social interactions on board provide resources for mitigating the negative effects of stressors. However, it is unclear whether they remain effective when ships' schedules are intense and workloads are high.

Adopting a Job Demands-Resources (JD-R) framework (Demerouti et al. 2001), this paper considers the effects of both job demands and resources on fatigue. More specifically, the purpose of this paper is to examine the effect of the quality of social interactions on board on fatigue, and to test whether this effect is affected by the ship's schedule. Data came from seven cargo ships engaged in short sea shipping in Europe and the Caribbean. Using a so-called incomplete repeated-measures design with data collected at four time points, the study combined information from documents with survey data collected during normal ship operation.

The study contributes to our understanding of stressors and strain in seafaring in several ways. Answering calls to examine a broader range of factors affecting strain (Oldenburg, Hogan, and Jensen 2013), it adds to the small number of studies that consider not only potential stressors, but also potential mitigating factors. Further, the study extends previous research by showing that although social interactions are an important resource for mitigating the effects of stressors on fatigue, the effect was significantly weaker when ships' schedules were more intense. Finally, compared to existing survey studies, the study allowed a stronger test of the hypotheses by collecting data on board (Oldenburg, Hogan, and Jensen 2013), by combining data from multiple sources (Podsakoff et al. 2003), and by using an incomplete repeated measures design and multilevel analysis (Snijders and Bosker 2012).

Figure 1

\section{Theoretical framework}

Figure 1 summarizes the theoretical model. Following the Job Demands-Resources (JD-R) model (Demerouti et al. 2001), both job demands and resources are expected to affect fatigue. However, what matters are not the objectively observable job demands and resources, but individuals' appraisal of the overall work pressure resulting from the combination of job demands and resources (Ganster and Rosen 2013; Gottlieb and Bergen 2010). Hence, perceived work pressure is expected to mediate the effects of job demands and resources on fatigue.

Building on previous research in the context of seafaring, relevant job demands include individuals' position on board, patterns of work/rest hours, and the ship's schedule. Social interactions on board can provide resources that reduce fatigue, but the effect may depend on the workload (reflected in the ship's schedule). Below each of these will be discussed in turn.

\subsection{Job demands in seafaring}

In a context where tasks and responsibilities are clearly defined and divided according to department (i.e., deck, engine, galley) and hierarchical level (Sampson 2013), individuals' position on board can affect their workload and thus levels of fatigue. However, few studies have examined this empirically. Field studies typically used samples drawn from only one department or did not report their findings separately by department (Arulanandam and Tsing 2009; Lützhöft et al. 2010; Ugurlu 2016; Wadsworth et al. 2006). A recent survey suggested that fatigue was higher among catering staff (Österman and Hult 2016), but it is unclear whether these findings only apply to those working on passenger ships.

Research Question 1: What is the effect of department on fatigue? 
Hierarchical level, when reported, was associated with higher levels of strain, probably due to the higher workload resulting from the leadership responsibilities and administrative tasks entailed by the position (Oldenburg et al. 2009; Österman and Hult 2016).

Hypothesis 1: Hierarchical level has a positive effect on fatigue, i.e. the higher the hierarchical level, the higher the reported level of fatigue.

Patterns of work and rest hours have received much attention (Oldenburg, Hogan, and Jensen 2013). Compared to day workers, sleep duration was shorter for watch keepers, especially in 2-watch systems, resulting in higher levels of fatigue (Oldenburg, Hogan, and Jensen 2013; Smith, Allen, and Wadsworth 2006). In addition, irregular work hours (often resulting from the ship's schedule, especially for individuals at higher hierarchical levels) and night work can cause circadian disruption, resulting in lower sleep quality and higher levels of fatigue (Akhtar and Utne 2015; Arulanandam and Tsing 2009; Oldenburg, Hogan, and Jensen 2013; Wadsworth et al. 2006). Thus, watch keeping, and especially night watches, are expected to be associated with higher levels of fatigue.

Hypothesis 2: Having night watches has a positive effect on fatigue, i.e. those having night watches will report higher levels of fatigue.

Although the number of work hours is recognized as one of the most important stressors (Oldenburg et al. 2009), hours surpassing legal limits may be underreported in self-report data as well as in official documents (Allen, Wadsworth, and Smith 2008). Hence, the ship's schedule, i.e. the number and pattern of days at sea, port calls and days in port, may be more useful as an indicator of the workload and the intensity of the work. Although in quantitative studies it has been difficult to separate the effect of days at sea because of high correlations with tour length and vessel type (Wadsworth et al. 2006, 2008), interview findings suggested that port calls (i.e. arrivals and departures) were associated with a higher workload and higher stress levels than days at sea (Prison, Dahlman, and Lundh 2013). Being in port has been associated with higher levels of strain (Bal, Arslan, and Tavacioglu 2015; Wadsworth et al. 2008). However, it has also been suggested that longer stays in port, perhaps allowing more leisure time and offering opportunities for going ashore, may reduce levels of strain (Kahveci 1999).

Hypothesis 3: The number of port calls has a positive effect on fatigue, i.e. the higher the number of port calls, the higher the reported level of fatigue.

Hypothesis 4: The number of days at sea has a negative effect on fatigue, i.e. the higher the number of days at sea, the lower the reported level of fatigue.

Research Question 2: What is the effect of days in port on fatigue?

\subsection{Social interactions as job resource}

As seafarers live and work on board, social interactions on board include both work-related interactions and informal interactions during leisure time (Knudsen 2004; Sampson 2013). They can range from teamwork, friendship and mutual support on the one hand to distrust, lack of collaboration and open conflict on the other hand. As is well-known from research on social capital and social support, positive interactions can be a source of social support (Adler and Kwon 2002; Gottlieb and Bergen 2010). This can include instrumental support, such as assisting colleagues with a heavy workload or taking over part of someone's watch, and emotional support, i.e. expressions of sympathy and caring, such as listening to another's problems or concerns. Thus, 
instrumental support can reduce the workload, one of the key stressors associated with fatigue, whereas emotional support can mitigate the emotional symptoms of fatigue.

Hypothesis 5: The quality of social interactions has a negative effect on fatigue, i.e. the more supportive the social interactions, the lower the reported level of fatigue.

Existing research in other contexts suggests that instrumental support in particular is more likely when potential supporters are not overburdened themselves, so that they have the time and energy to assist others (Barnes et al. 2008; Chang, Johnson and Yang 2007). Thus, as the overall workload on board increases, for instance as a result of a higher number of port calls, fewer and fewer individuals will be able to assist others. In this situation, even when social interactions on board are supportive, they are less likely to be effective in providing social support, and consequently their effect on fatigue diminishes.

Hypothesis 6: The effect of the quality of social interactions on fatigue depends on the number of port calls. The lower the number of port calls, the stronger the negative effect of supportive interactions on fatigue.

\subsection{Individuals' perceptions as mediator}

Individuals differ in their perception of job demands and resources, and it is these perceptions that affect how stressful a situation appears to an individual (Ganster and Rosen 2013). Thus, Grebner, Semmer, and Elfering (2005) found that correlations with strain were stronger for perceived than for observer-rated demands. Similarly, Gottlieb and Bergen (2010) concluded that it is perceived support, rather than actual support, that buffers the negative effects of stressors.

Theoretical work suggests that in their appraisal of the situation, individuals will take into account both potential stressors and the resources available to cope with them (Ganster and Rosen 2013; Bakker, Demerouti, and Sanz-Vergel 2014), resulting in an overall assessment of the level of work pressure. Individuals with copious resources may experience stressors less intensely, or perhaps even as welcome challenge, whereas individuals with less resources may feel overwhelmed by the pressure (Courtright, Colbert, and Choi 2014). Thus, individuals' perceptions of overall work pressure are expected to mediate the effects of job demands and resources on fatigue.

Hypothesis 7: The effects of department, hierarchical level, night watches, port calls, days at sea, days in port, quality of social interactions, and the interaction between quality of social interactions and port calls on fatigue are mediated by perceived work pressure.

\section{Data collection}

Data were collected from a convenience sample of seven cargo ships, at four time points with about 3 months in between (Table 1). The ships engaged in short sea shipping in Europe and the Caribbean, transporting a variety of cargoes such as containers, pallets, wheeled cargo and other unit load cargo. Their size ranged from about 4000 to 12000 deadweight tons, with crews of about 10 to 20 persons on board. Not all ships were included at all time points; this was because not all ships were in regular traffic at each time point, and, to avoid respondent fatigue, each ship was included at most three times.

Data on perceived work pressure, quality of social interactions, position on board, work characteristics, demographic information and general information on ships' schedules was collected at all four time points. In addition, at time points 3 and 4, a measure of fatigue was 
added, and ships' schedules were recorded in more detail (see section 3.3.) to measure night arrivals and departures, and respondents' schedules in the week before they completed the survey.

For sake of convenience, the data available from time points 1 through 4 will be referred to as 'Dataset A'. 'Dataset B' refers to a subset of these data, namely those collected at time points 3 and 4. It includes the same variables as Dataset A, plus measures of fatigue, night arrivals and departures, and respondents' schedules during the previous week.

\section{Table 1}

Data came from multiple sources: employee surveys on board of the ships, company records, and the Marine Traffic website. Questionnaires were available in English, Finnish and Swedish, i.e. the working languages on board and/or crew members' first languages. The questionnaire was prepared in English and translated into Swedish by the author and a native speaker of Swedish. The Swedish version was then translated into Finnish by a native speaker, and back-translated in order to identify and correct any differences (Brislin, 1970). A pilot test with two crew members was conducted to ensure that questions were clear and easy to answer.

At each survey time point, all individuals who were employed on a vessel included in the study were invited to participate in the survey. In total, 156 individuals were employed on board during one or more survey time points. Of these, 127 individuals participated in the survey at least once (response rate at Time 1: 70.1\%; Time 2: 86.5\%; Time 3: 94.0\%; Time 4: 63.0\%). This provided 235 responses (of 311 possible responses) in Dataset A (overall response rate: 75.6\%), and 110 responses (of 150 possible responses) in Dataset B (overall response rate: $73.3 \%$ ). In Dataset B, three responses were excluded due to missing data, leaving 107 usable responses.

Most of the 127 respondents were men (Table 2). Average age was 37 years (range: 20 to 65 years), average organizational tenure was 7 years (range: 0 to 27 years). Most had permanent contracts. $62 \%$ worked on deck, $28 \%$ worked in the engine room, and $10 \%$ in the galley. About three quarters of the respondents were officers. The figures were similar for the subset of respondents in Dataset B. There were no significant differences between respondents and nonrespondents with regard to gender, contract, department, hierarchical level and (where this was known for non-respondents) age and organizational tenure.

Table 2

\subsection{Perceived work pressure, fatigue and quality of social interactions}

Survey responses provided information on perceived work pressure, fatigue, and the quality of social interactions on board. Perceived work pressure was measured with two items that assessed dissatisfaction and perceived problems with the work pressure. The first was 'How satisfied or dissatisfied are you with the work pressure?', with answer categories from 1 = 'very dissatisfied' to $7=$ 'very satisfied'. For the analyses, the item was reverse-coded. In the second item, respondents were asked to rate to what extent they had noticed or experienced problems with the work pressure. Answers categories were coded $1=$ 'not at all', $3=$ 'a little', $5=$ 'to some extent', and $7=$ 'very much'. The two items were strongly correlated $(r=0.47)$, and were combined by taking the average of respondents' answers.

Fatigue was measured at time points 3 and 4 (Dataset B) with five items adapted from Sasaki et al. (2007) and Glise et al. (2010). Items assessed cognitive, emotional and physical symptoms of fatigue. Respondents were asked to rate how often during the previous week they had 'had trouble concentrating or remembering things', 'been irritable or got angry easily', 'felt 
exhausted (except for after sports)', 'felt very tired during work', 'had sleeping problems (for instance, not being able to fall asleep, or not sleeping well)', and 'felt ill or not really well'. Answer categories were 1 = 'never', 2 = 'once', $3=$ 'several times' and 4 = 'every day'. Cronbach's alpha was 0.78 . After checking that a sufficiently high Cronbach's alpha and a onefactor structure in a principal component analysis justified combining the items, the scale was formed by taking the mean of each respondent's responses.

The quality of social interactions on board was measured with four items: two items on collaboration and two items on interpersonal relations on board. The first three items were 'How satisfied or dissatisfied are you with the collaboration with other crew members on [ship name]?', 'It is difficult for me to ask others on board for help' (reverse coded), and 'I feel like "part of the family" on [ship name]'. Answer categories ranged from $1=$ 'very dissatisfied'/"not at all accurate' to $7=$ 'very satisfied'/'completely accurate'. In the last item, respondents were asked to rate to what extent they had noticed or experienced problems with 'personal conflicts among managers or employees', with answer categories coded $1=$ 'not at all', $3=$ 'a little', $5=$ 'to some extent', and $7=$ 'very much'. For the analyses, this item was reverse-coded. The scale was formed by taking the mean of each respondent's responses, after confirming that Cronbach's alpha $(\alpha=$ 0.74 ) and a one-factor structure in a principal component analysis justified combining the items.

\subsection{Position, work characteristics and demographic information}

Information on watch schedules and position on board came from company records. Department was measured with dummy variables for deck, engine, and galley.

Hierarchical level was coded ' 4 ' for masters, ' 3 ' for chief engineers and chief officers, ' 2 ' for first engineers, ' 1 ' for deck officers, second engineers, boatswains and cook stewards, and ' 0 ' for all others.

A dummy variable 'night watches' was coded ' 1 ' for individuals who had all or part of their watch between 00:00 and 06:00 (ship's time), and ' 0 ' for all others.

Demographic information on respondents' gender $(0=$ 'man', $1=$ 'woman'), age, organizational tenure, and type of contract ( 0 = 'fixed-term', $1=$ 'permanent') was obtained from survey responses and/or company records.

\subsection{Ships' schedules}

Information on port calls was obtained from schedules published on company web sides and from Marine Traffic (https://www.marinetraffic.com). Based on this, it was possible to calculate the number of days at sea and in port, the number of arrivals and departures, and (for time points 3 and 4, Dataset B) the number of night arrivals and departures.

A calendar day was coded as a 'day at sea' if the ship was at sea or at anchor outside a port during the whole day (from midnight to midnight). Thus, the number of days at sea was determined by counting the calendar days coded as 'days at sea'. Similarly, a calendar day was coded as a 'day in port' if the ship was in port during the whole day (from midnight to midnight). The number of arrivals and departures was calculated from the number of port calls, each of which involved one arrival and one departure; for ports with locks, one arrival and one departure were added. Arrivals and departures between 00:00 and 06:00 (ship's time) were considered 'night time'.

For each ship, these variables were calculated as average per week during each round of the survey. These variables will be referred to as 'ship's days at sea', 'ship's arrivals and departures' and 'ship's days in port', respectively. As shown in Table 3, ships' schedules varied from daily port calls and sea voyages of less than a full calendar day (e.g., Caribbean ${ }^{1}$, time point 1) to schedules with several full days at sea and few arrivals and departures per week (e.g., 
Mediterranean, time point 4). Port calls typically lasted less than a day, reflected in low average numbers of days in port.

To obtain more detailed information on schedules experienced by individual respondents, at time points 3 and 4 (Dataset B) respondents were asked to indicate the date when they completed the survey. Based on this, each person's response could be linked to information on the ship's schedule. In this way it was possible to determine the schedule experienced by each respondent during the week before he or she completed the survey. The resulting variables will be referred to as 'respondent's [days at sea/arrivals and departures/night arrivals and departures/days in port] during the previous week'. As shown in Table 4, the schedules experienced by respondents in the week before they completed the survey could vary considerably, even for those working on the same ship. Differences were smaller when ships had relatively regular schedules (e.g., Mare, time point 3), and disappeared when respondents happened to complete the survey on the same day (Caribbean, time point 4).

Table 3

Table 4

\section{Data analysis}

Given the structure of the data - an incomplete repeated-measures design, where information was collected from individuals on different ships at one to four time points - hypotheses were tested using multilevel analysis (Snijders and Bosker 2012). This accounted for interdependencies between responses at different time points (Level 1) nested in individuals (Level 2) nested in ships (Level 3). Dataset A included 235 responses at time points 1 through 4, provided by 127 individuals on seven ships. Dataset B included 107 responses at time points 3 and 4, by 89 individuals on six ships. To reduce potential multicollinearity problems when testing interaction effects, all independent variables (except for dummy variables) were centered around the grand mean, and interaction terms were calculated from the centered variables.

Models were specified using iterated generalized least squares (IGLS) estimation in MLwiN 2.36 (Rasbash et al. 2016). The theoretical model was tested using the approach recommended by Baron and Kenny (1986). In the first step, the dependent variable (here: fatigue) and the mediator (here: perceived work pressure) were each regressed on the independent variables. In the second step, the mediator was added to the model with fatigue as dependent variable.

To take advantage of all available data, for perceived work pressure as dependent variable, the analyses were based on Dataset A (Table 7, Models 1 and 2). For models with fatigue as dependent variable, the analyses were based on Dataset B (Table 7, Models 3 to 9).

Given the smaller number of cases in Dataset B, and to minimize multicollinearity problems due to high correlations between variables measuring characteristics of ships' schedules, two separate sets of models were calculated: one with ships' schedules, and one with respondents' schedules during the previous week. For reasons of parsimony, variables were only retained when they had significant effects in Model 4 and/or Model 5. Demographic characteristics had no significant effects, and were therefore not included in the models shown in Table 7. 
Table 6

\section{Results}

Descriptive statistics and correlations are shown in Tables 5 and 6. Answers to the questions on fatigue suggested that on average, respondents had experienced each of the symptoms addressed in the items about once during the previous week. However, answers showed considerable variation: four respondents had not experienced any of the symptoms during the previous week, whereas six respondents had experienced each of them 'several times' or 'every day'.

\section{Table 7}

As indicated by the variances (Table 7, Models 1 and 3), there were considerable differences between responses at different time points and between individuals, whereas differences between ships were less pronounced. Adding the independent variables significantly reduced the variances, explaining all between-ship differences and a large part of the differences between individuals and different time points. As noted above, for reasons of parsimony, main effects that were not significant in either Model 4 or Model 5 were not included in the models in Table 7, but will be discussed when relevant.

Figure 2

Turning to Research Question 1, as illustrated in Figure 2, on average those working on deck perceived higher work pressure than those working in the engine room $(t(213)=2.963, p<$ $.01)$, and they, in turn, perceived somewhat higher work pressure than those working in the galley $(t(84)=1.240$, n.s.). For fatigue, answers followed a similar pattern, although the differences between departments were nonsignificant. In the multilevel analyses, the dummy variable 'deck' had a positive effect on fatigue which reached significance in Model $4(\gamma=0.241$, s.e. $=0.114, p$ $<.05)$.

Hierarchical level had a significant positive effect on fatigue (Model 4: $\gamma=0.120$, s.e. $=$ $0.044, p<.01$; Model 5: $\gamma=0.119$, s.e. $=0.044, p<.01)$, suggesting that those at higher hierarchical levels experienced higher levels of fatigue. This supported Hypothesis 1.

By contrast, night watches had no effect on fatigue in the multilevel analyses. Additional $t$ tests showed no significant difference in fatigue between those who had night watches and those who had not $(t(105)=-0.254$, n.s.). Thus, Hypothesis 2 was rejected.

The number of arrivals and departures had a significant positive effect on fatigue, whether considering the ship's schedule (Model 4: $\gamma=0.020$, s.e. $=0.008, p<.05$ ) or respondents' schedules during the previous week (Model 5: $\gamma=0.016$, s.e. $=0.006, p<.01$ ). This supported Hypothesis 3. Additional analyses showed that night arrivals and departures had a significant positive effect on fatigue $(\gamma=0.042$, s.e. $=0.018, p<.05)$ when included in Model 5 instead of the number of arrivals and departures. When adding both variables, both had small positive but nonsignificant effects (arrivals and departures: $\gamma=0.010$, s.e. $=0.009$, n.s.; night arrivals and departures: $\gamma=0.031$, s.e. $=0.020$, n.s. $)$.

For days at sea, the effect was negative as predicted, but weaker than expected. Ship's days at sea, when included instead of arrivals and departures, had a significant negative effect $(\gamma=-$ 0.071 , s.e. $=0.036, p<.05)$. However, the improvement in the model was stronger when including arrivals and departures $(\Delta-2 \log$-likelihood $=6.494, p<.05)$ rather than days at sea $(\Delta-2 \log$ - 
likelihood $=3.894, p<.05)$. When both effects were included, the effect of days at sea became nonsignificant. Considering respondents' schedules during the previous week, the effect of days at sea was nonsignificant when added to the model $(\gamma=-0.074$, s.e. $=0.104$, n.s. $)$ or when included instead of the number of arrivals and departures $(\gamma=-0.050$, s.e. $=0.039$, n.s. $)$. This provided limited support for Hypothesis 4.

Regarding Research Question 2, the results suggested that days in port did not affect fatigue. Days in port had no effect on fatigue when added to Model $4(\gamma=0.074$, s.e. $=0.249$, n.s. $)$ or Model 5 ( $\gamma=-0.008$, s.e. $=0.097$, n.s.), or when used instead of number of arrivals and departures (Model 4: $\gamma=-0.172$, s.e. $=0.235$, n.s.; Model 5: $\gamma=-0.054$, s.e. $=0.099$, n.s.).

The quality of social interactions had a significant negative effect in the multilevel analyses (Model 4: $\gamma=-0.142$, s.e. $=0.054, p<.01$; Model 5: $\gamma=-0.148$, s.e. $=0.054, p<.01$ ). This supported Hypothesis 5.

The interaction between the quality of social interactions and respondents' arrivals and departures during the previous week had a significant effect (Model 7: $\gamma=0.011$, s.e. 0.005, $p<$ $.05)$; a similar effect was found for respondents' night arrivals and departures $(\gamma=0.031$, s.e. $0.011, p<.01)$. Supportive interactions were associated with significantly lower levels of fatigue when the number of arrivals and departures was low, whereas for those reporting less supportive interactions, fatigue was higher, regardless of the number of arrivals and departures (Figure 3). By contrast, when considering the ship's schedule (Model 6), the interaction was nonsignificant. This supported Hypothesis 6 when considering respondents' schedules during the previous week, but not when considering the ship's schedule more generally.

Figure 3

The results for perceived work pressure as dependent variable were similar to those for fatigue, both in analyses based on Dataset A (Model 2) and in analyses based on Dataset B (not shown). Department, hierarchical level, and arrivals and departures had significant positive effects, whereas the quality of social interactions had a significant negative effect. Days at sea had a negative effect, although its significance depended on whether it was included in combination with arrivals and departures. When added to the model with fatigue as dependent variable, perceived work pressure itself had a significant positive effect on fatigue (Model 8: $\gamma=0.226$, s.e. $=0.037, p<.001$; Model 9: $\gamma=0.223$, s.e. $=0.036, p<.001$ ). Except for the interaction between quality of social interactions and respondents' arrivals and departures, all effects became nonsignificant, suggesting that perceived work pressure mediated their effects on fatigue. This provided partial support for Hypothesis 7.

\section{Discussion and conclusions}

In line with the Job Demands-Resources model (Demerouti et al. 2001), the findings indicated that both job demands (here: department, hierarchical level, number of port calls) and resources (here: quality of social interactions) mattered. Almost all effects were mediated by perceived work pressure (Ganster and Rosen 2013).

Fatigue levels differed depending on individuals' position on board, with those working on deck and those at higher hierarchical levels reporting more fatigue. Contrary to previous research (Österman and Hult 2016), fatigue levels were lowest among catering staff, perhaps due to differences in the types of vessels studied.

Night watches had no effect on fatigue or perceived work pressure. This may be due to the context of the study (i.e., short sea shipping), where the timing of port calls and the higher workload associated with them may lead to frequent adjustments in the actual number and timing 
of work hours (Akhtar 2014; Allen, Wadsworth, and Smith 2008; Uğurlu 2016). Thus, as other crew members may be required to work at night as well, the effect of night watches may become more difficult to distinguish. Further, in this situation, fixed watches (including night watches) may be an advantage because they allow circadian re-adaptation (Parkes 2012), whereas irregular work hours continue to cause circadian disruption, resulting in higher levels of fatigue (Arulanandam and Tsing 2009; Oldenburg, Hogan, and Jensen 2013; Parkes 2012).

As expected, fatigue was affected by ships' schedules, notably the number of port calls and (to a lesser extent) the number of days at sea. However, high correlations between these variables made it difficult to disentangle their effects. Night arrivals and departures seemed to play a role as well, but again the number of cases was too small to establish whether they made a separate contribution beyond the total number of port calls. With regard to days in port, as noted above, previous research suggested contradictory effects. In this study, days in port had no effect on fatigue, probably because for the ships included here, days in port could involve intense cargo operations, as well as waiting time (cf. Johnson and Styhre 2015), so that the effects may have cancelled each other out.

The quality of social interactions, as a source of social support, was expected to reduce levels of fatigue. In line with previous research (Rydstedt and Lundh 2010; Wadsworth et al. 2008), the results of this study supported this idea. Supportive interactions among crew members significantly reduced levels of fatigue, although, importantly, only up to a certain point: the effect became weaker as the number of port calls, and hence the overall workload on board, increased. Interestingly, this interaction was only significant when considering the more fine-grained, respondent-specific measure of port calls, suggesting a short-term reduction in the effectiveness of social support. It was also the only effect not mediated by perceived work pressure. Clearly more research will be needed to better understand the role of social interactions, and the conditions under which they can mitigate the effects of stressors.

\subsection{Limitations}

Small sample sizes and confounds due to high correlations between variables are a well-known problem in maritime field studies (Oldenburg, Hogan, and Jensen 2013). The present study is no exception. For this reason, it was not possible to differentiate between the effects of e.g. days at sea and number of port calls, or to investigate the effects of the timing of respondents' work hours in more detail (e.g., comparing different watch systems). The small number of crew on each ship, and the fact that not all ships could be included at all time points, also meant that there were too few cases in successive waves to conduct longitudinal analyses. This would have allowed stronger conclusions about the direction of causality between social interactions, perceived work pressure and fatigue.

Although there was considerable variation in ships' schedules, the fact that this study was limited to cargo ships engaged in short sea shipping raises questions about generalizability. Indeed, the inconsistencies between this study and previous research concerning the effect of department indicated that effects might be context dependent, suggesting the need for further research comparing different types of vessels (e.g., passenger ships, different types of cargo ships) and routes (e.g., short sea vs. deep sea shipping).

\subsection{Conclusion}

As noted by Oldenburg, Hogan, and Jensen (2013), there is a need for field studies examining a broader range of stressors in seafaring. Answering this call, the findings of this study suggested the importance of considering both potential stressors (i.e. individuals' position on board, characteristics of ships' schedules) and mitigating factors (i.e. quality of social interactions). Building on research from across the social sciences showing that individuals' thought and 
behaviour is shaped by their position in the social structure (Burt 2000), future research on stressors and strain in seafaring should pay particular attention to social interactions on board. Findings in the present study, as well as research on other aspects of seafaring (Knudsen 2004; Oltedal and Wadsworth 2010), suggest that this may present promising avenues for further research.

\section{Notes}

1. To maintain confidentiality, all ship names used in this paper are pseudonyms.

\section{Acknowledgements}

I would like to thank Jannika Lassus and Mervi Vuolama-Ristola for their help with the Swedish and Finnish translations of the survey, and Mira Karjalainen for advice on nautical terminology in Finnish. Special thanks to the masters and crews of the ships who participated in this study for their hospitality, and to the masters and office personnel for their help with practical matters. Most of all: many thanks to all who participated in the surveys.

\section{Funding}

Data collection was supported by grants from the Hanken Foundation and the Dr. h.c. Marcus Wallenberg Foundation for Promoting Research in Business Administration.

\section{Disclosure statement}

No potential conflict of interest was reported by the author.

\section{References}

Adler, P. S., and S.-W. Kwon. 2002. "Social Capital: Prospects for a New Concept." Academy of Management Review 27 (1): 17-40. doi: 10.5465/AMR.2002.5922314.

Akhtar, M. J. 2014. "Fatigue at Sea: A Manning Problem.” Journal of Maritime Research 11 (3): $27-42$.

Akhtar, M. J., and I. B. Utne. 2015. "Common Patterns in Aggregated Accident Analysis Charts from Human Fatigue-Related Groundings and Collisions at Sea." Maritime Policy \& Management 42 (2): 186-206. doi: 10.1080/03088839.2014.926032.

Allen, P., E. Wadsworth, and A. Smith. 2008. "Seafarers' Fatigue: A Review of the Recent Literature." International Maritime Health 59 (1-4): 81-92.

Allianz Global Corporate \& Specialty. 2015. Safety and Shipping Review 2015: An Annual Review of Trends and Developments in Shipping Losses and Safety. Munich: Allianz Global Corporate \& Specialty AG. Available at http://www.agcs.allianz.com/insights/white-papers-and-casestudies/safety-and-shipping-review-2015.

Arulanandam, S., and G. C. C. Tsing. 2009. "Comparison of Alertness Levels in Ship Crew: An Experiment on Rotating versus Fixed Watch Schedules." International Maritime Health 60 (1-2): 6-9. 
Bakker, A. B., E. Demerouti, and A. I. Sanz-Vergel. 2014. "Burnout and Work Engagement: The JD-R Approach." Annual Review of Organizational Psychology and Organizational Behavior 1: 389-411. doi: 10.1146/annurev-orgpsych-031413-091235.

Bal, E., O. Arslan, and L. Tavacioglu. 2015. "Prioritization of the Causal Factors of Fatigue in Seafarers and Measurement of Fatigue with the Application of the Lactate Test." Safety Science 72: 46-54. doi: 10.1016/j.ssci.2014.08.003.

Barnes, C. M., J. R. Hollenbeck, D. T. Wagner, D. S. DeRue, J. D. Nahrgang, and K. M. Schwind. 2008. "Harmful Help: The Costs of Backing-Up Behavior in Teams." Journal of Applied Psychology 93 (3): 529-539. doi: 10.1037/0021-9010.93.3.529.

Baron, R. M., and D. A. Kenny. 1986. "The Moderator-Mediator Variable Distinction in Social Psychological Research: Conceptual, Strategic, and Statistical Considerations." Journal of Personality and Social Psychology 51 (6): 1173-1182. doi: 10.1037/0022-3514.51.6.1173.

Bloor, M., M. Thomas, and T. Lane. 2000. "Health Risks in the Global Shipping Industry: An Overview." Health, Risk \& Society 2 (3): 329-340. doi: 10.1080/713670163.

Brislin, R. W. 1970. "Back-Translation for Cross-Cultural Research.” Journal of Cross-Cultural Psychology 1 (3): 185-216.

Burt, R. S. 2000. "The Network Structure of Social Capital." Research in Organizational Behavior 22: 345-423. doi: 10.1016/S0191-3085(00)22009-1.

Chang, C.-H., R. E. Johnson, L.-Q. Yang. 2007. "Emotional Strain and Organizational Citizenship Behaviours: A Meta-Analysis and Review." Work \& Stress 21 (4): 312-332. doi: 10.1080/02678370701758124.

Courtright, S. H., A. E. Colbert, and D. Choi. 2014. "Fired Up or Burned Out? How Developmental Challenge Differentially Impacts Leader Behavior." Journal of Applied Psychology 99 (4): 681-696. doi: 10.1037/a0035790.

Demerouti, E., A. B. Bakker, F. Nachreiner, and W. B. Schaufeli. 2001. "The Job DemandsResources Model of Burnout." Journal of Applied Psychology 86 (3): 499-512. doi: 10.1037/0021-9010.86.3.499.

Fenstad, J., Ø. Dahl, and T. Kongsvik. 2016. "Shipboard Safety: Exploring Organizational and Regulatory Factors." Maritime Policy \& Management 43 (5): 552-568. doi: 10.1080/03088839.2016.1154993.

Ganster, D. C., and C. C. Rosen. 2013. "Work Stress and Employee Health: A Multidisciplinary Review.” Journal of Management 39 (5): 1085-1122. doi: 10.1177/0149206313475815.

Glise, K., E. Hadzibajramovic, I. H. Jonsdottir, and G. Ahlborg. 2010. "Self-Reported Exhaustion: A Possible Indicator of Reduced Work Ability and Increased Risk of Sickness Absence among Human Service Workers." International Archives of Occupational and Environmental Health 83 (5): 511-520. doi: 10.1007/s00420-009-0490-x.

Gottlieb, B. H., and A. E. Bergen. 2010. "Social Support Concepts and Measures." Journal of Psychosomatic Research 69 (5): 511-520. doi:10.1016/j.jpsychores.2009.10.001. 
Grebner, S., N. K. Semmer, and A. Elfering. 2005. "Working Conditions and Three Types of Well-Being: A Longitudinal Study with Self-Report and Rating Data." Journal of Occupational Health Psychology 10 (1): 31-43. doi: 10.1037/1076-8998.10.1.31.

Johnson, H., and L. Styhre. 2015. "Increased Energy Efficiency in Short Sea Shipping Through Decreased Time in Port." Transportation Research Part A 71: 167-178. doi: 10.1016/j.tra.2014.11.008.

Kahveci, E. 1999. Fast Turnaround Ships and Their Impact on Crews. Cardiff: Seafarers International Centre. Available at http://www.sirc.cf.ac.uk/SIRC_Free_Online_Reports.aspx.

Knudsen, F. (2004). "If you are a good leader I am a good follower": Working and leisure relations between Danes and Filipinos on board Danish vessels. Arbejds- og Maritimmedicinsk Publicationsserie, $\quad$ Report No. $9 . \quad$ Available at http://static.sdu.dk/mediafiles/Files/Om_SDU/Institutter/Ist/MaritimSundhed/Rapporter/report9 2004.pdf

Lützhöft, M., A. Dahlgren, A. Kirchner, B. Thorslund, and M. Gillberg. 2010. "Fatigue at Sea in Swedish Shipping: A Field Study." American Journal of Industrial Medicine 53 (7): 733-740. doi: 10.1002/ajim.20814.

Macrae, C. 2009. "Human Factors at Sea: Common Patterns of Error in Groundings and Collisions." Maritime Policy \& Management 36 (1): 21-38. doi: 10.1080/03088830802652262.

Oldenburg, M., B. Hogan, and H.-J. Jensen. 2013. "Systematic Review of Maritime Field Studies About Stress and Strain in Seafaring." International Archives of Occupational and Environmental Health 86 (1): 1-15. doi: 10.1007/s00420-012-0801-5.

Oldenburg, M., H.-J. Jensen, U. Latza, and X. Baur. 2009. "Seafaring Stressors aboard Merchant and Passenger Ships." International Journal of Public Health 54 (2): 96-105. doi: 10.1007/s00038-009-7067-z.

Oltedal, H., and E. Wadsworth. 2010. "Risk Perception in the Norwegian Shipping Industry and Identification of Influencing Factors." Maritime Policy \& Management 37 (6): 601-623. doi: 10.1080/03088839.2010.514954.

Österman, C., and C. Hult. 2016. "Administrative Burdens and Over-Exertion in Swedish Short Sea Shipping." Maritime Policy \& Management 43 (5): 569-579. doi: 10.1080/03088839.2016.1154994.

Parkes, K. R. 2012. "Shift Schedules on North Sea Oil/Gas Installations: A Systematic Review of Their Impact on Performance, Safety and Health." Safety Science 50 (7): 1636-1651. doi: 10.1016/j.ssci.2012.01.010.

Podsakoff, P. M., S. B. MacKenzie, J.-Y. Lee, and N. P. Podsakoff. 2003. "Common Method Biases in Behavioral Research: A Critical Review of the Literature and Recommended Remedies.” Journal of Applied Psychology 88 (5): 879-903. doi: 10.1037/0021-9010.88.5.879.

Poulsen, T. R., H. Burr, H. L. Larsen, and J. R. Jepsen. 2014. "Health of Danish Seafarers and Fishermen 1970-2010: What Have Register-Based Studies Found?" Scandinavian Journal of 
Public Health 42 (6): 534-545. doi: 10.1177/1403494814534538.

Prison, J., J. Dahlman, and M. Lundh. 2013. "Ship Sense: Striving for Harmony in Ship Manoeuvring." WMU Journal of Maritime Affairs 12 (1): 115-127. doi: 10.1007/s13437-0130038-5.

Rasbash, J., W. Browne, M. Healy, B. Cameron, and C. Charlton. 2016. MLwiN, version 2.36. Centre for Multilevel Modelling, University of Bristol, UK.

Rydstedt, L. W., and M. Lundh. 2010. "An Ocean of Stress? The Relationship between Psychosocial Workload and Mental Strain among Engine Officers in the Swedish Merchant Fleet.” International Maritime Health 61 (3): 168-175.

Sampson, H. 2013. International Seafarers and Transnationalism in the Twenty-First Century. Manchester: Manchester University Press.

Sampson, H., and M. Thomas. 2003. "The Social Isolation of Seafarers: Causes, Effects, and Remedies." International Maritime Health 54 (1-4): 58-67.

Sasaki, T., K. Iwasaki, I. Mori, N. Hisanaga, and E. Shibata. 2007. "Overtime, Job Stressors, Sleep/Rest, and Fatigue of Japanese Workers in a Company." Industrial Health 45 (2): 237-246. doi: 10.2486/indhealth.45.237.

Smith, A., P. Allen, and E. Wadsworth. 2006. Seafarer Fatigue: The Cardiff Research Programme. Centre for Occupational Health and Psychology, Cardiff University, Cardiff, UK. Available at http://orca.cf.ac.uk/48167.

Snijders, T. A. B., and R. J. Bosker. 2012. Multilevel Analysis: An Introduction to Basic and Advanced Multilevel Modeling. Second Edition. Los Angeles: Sage.

Uğurlu, O. 2016. "A Case Study Related to the Improvement of Working and Rest Hours of Oil Tanker Deck Officers." Maritime Policy \& Management 43 (4): 524-539. doi: 10.1080/03088839.2015.1040476.

Wadsworth, E. J. K., P. H. Allen, R. L. McNamara, and A. P. Smith. 2008. "Fatigue and Health in a Seafaring Population." Occupational Medicine 58 (3): 198-204. doi:10.1093/occmed/kqn008.

Wadsworth, E. J. K., P. H. Allen, B. T. Wellens, R. L. McNamara, and A. P. Smith. 2006. "Patterns of Fatigue among Seafarers during a Tour of Duty." American Journal of Industrial Medicine 49 (10): 836-844. doi: 10.1002/ajim.20381.

Williamson, A., D. A. Lombardi, S. Folkard, J. Stutts, T. K. Courtney, and J. L. Connor. 2011. "The Link between Fatigue and Safety." Accident Analysis and Prevention 43 (2): 498-515. doi: 10.1016/j.aap.2009.11.011. 
Table 1. Overview of the ships included in Datasets A and B

\begin{tabular}{llcccc}
\hline $\begin{array}{l}\text { Ship name } \\
\text { (pseudonym) }\end{array}$ & Area & Time point 1 & Time point 2 & Time point 3 & Time point 4 \\
\hline Meri & Northern Europe & Dataset A & Dataset A & Dataset A \& B & - \\
Baltic & Northern Europe & Dataset A & Dataset A & - & Dataset A \& B \\
Noordzee & Northern Europe & Dataset A & - & - & - \\
Nordic Coast & Northern Europe & - & - & - & Dataset A \& B \\
Mare & Mediterranean & - & Dataset A & Dataset A \& B & Dataset A \& B \\
Mediterranean & Mediterranean & - & - & - & Dataset A \& B \\
Caribbean & Caribbean & Dataset A & - & - & Dataset A \& B \\
\hline
\end{tabular}

Table 2. Demographic characteristics of respondents

\begin{tabular}{|c|c|c|c|c|}
\hline & \multicolumn{2}{|c|}{ Dataset A } & \multicolumn{2}{|c|}{ Dataset B } \\
\hline & Mean & SD & Mean & SD \\
\hline Gender (1 = woman $)$ & 0.05 & 0.21 & 0.03 & 0.18 \\
\hline Age & $36.74^{\mathrm{a}}$ & 10.70 & 36.40 & 10.11 \\
\hline Organizational tenure (in years) & 7.14 & 6.31 & 6.99 & 6.37 \\
\hline Contract $(1=$ permanent $)$ & 0.82 & 0.39 & 0.85 & 0.36 \\
\hline Department: deck & 0.62 & 0.49 & 0.62 & 0.49 \\
\hline Department: engine & 0.28 & 0.45 & 0.30 & 0.46 \\
\hline Department: galley & 0.10 & 0.30 & 0.08 & 0.27 \\
\hline Officers ${ }^{\mathrm{b}}$ & 0.72 & 0.45 & 0.79 & 0.41 \\
\hline Number of individual respondents & \multicolumn{2}{|c|}{127} & \multicolumn{2}{|c|}{89} \\
\hline
\end{tabular}

Notes: ${ }^{a}$ Information missing for two individuals. ${ }^{b}$ Percentage of individuals with values of ' 1 ' or higher on the variable 'Hierarchical level'. 
Table 3. Ships' schedules

\begin{tabular}{|c|c|c|c|c|}
\hline $\begin{array}{c}\text { Ship name } \\
\text { (pseudonym) }\end{array}$ & $\begin{array}{l}\text { Time } \\
\text { point }\end{array}$ & Days at sea ${ }^{a}$ & $\begin{array}{c}\text { Arrivals and } \\
\text { departures }^{\mathrm{a}}\end{array}$ & Days in port \\
\hline \multirow[t]{3}{*}{ Meri } & 1 & 3.39 & 6.69 & 0.11 \\
\hline & 2 & 2.38 & 10.25 & 0.38 \\
\hline & 3 & 2.28 & 10.09 & 0.65 \\
\hline \multirow[t]{3}{*}{ Baltic } & 1 & 3.39 & 7.11 & 0.11 \\
\hline & 2 & 2.82 & 9.58 & 0.12 \\
\hline & 4 & 2.38 & 9.50 & 0.38 \\
\hline Noordzee & 1 & 3.15 & 8.05 & 0.35 \\
\hline Nordic Coast & 4 & 1.13 & 13.25 & 0.25 \\
\hline \multirow[t]{3}{*}{ Mare } & 2 & 0.00 & 12.88 & 0.63 \\
\hline & 3 & 0.00 & 17.40 & 0.00 \\
\hline & 4 & 0.10 & 20.33 & 0.10 \\
\hline Mediterranean & 4 & 4.34 & 3.08 & 0.28 \\
\hline \multirow[t]{2}{*}{ Caribbean } & 1 & 0.00 & 19.00 & 0.00 \\
\hline & 4 & 0.00 & 21.00 & 0.50 \\
\hline
\end{tabular}

Note: ${ }^{a}$ Average per week during each time point of the survey.

Table 4. Respondents' schedules during the previous week

\begin{tabular}{|c|c|c|c|c|c|c|c|c|c|}
\hline \multirow{2}{*}{$\begin{array}{c}\text { Ship name } \\
\text { (pseudonym) }\end{array}$} & \multirow{2}{*}{$\begin{array}{l}\text { Time } \\
\text { point }\end{array}$} & \multicolumn{2}{|c|}{ Days at sea } & \multicolumn{2}{|c|}{$\begin{array}{c}\text { Arrivals and } \\
\text { departures (total) }\end{array}$} & \multicolumn{2}{|c|}{$\begin{array}{l}\text { Night arrivals } \\
\text { and departures }\end{array}$} & \multicolumn{2}{|c|}{ Days in port } \\
\hline & & Min-max & Mean & Min-max & Mean & Min-max & Mean & Min-max & Mean \\
\hline Meri & 3 & $0-4$ & 2.27 & $3-20$ & 13.09 & $0-3$ & 1.64 & $0-3$ & 0.50 \\
\hline Baltic & 4 & $1-3$ & 2.30 & $6-18$ & 10.40 & $1-5$ & 2.20 & $0-0$ & 0.00 \\
\hline Nordic Coast & 4 & $0-3$ & 1.00 & $11-22$ & 17.27 & $0-3$ & 1.82 & $0-1$ & 0.09 \\
\hline Mare & 3 & $0-0$ & 0.00 & $16-20$ & 17.50 & $0-3$ & 1.27 & $0-0$ & 0.00 \\
\hline & 4 & $0-1$ & 0.22 & $13-37$ & 20.94 & $0-12$ & 4.00 & $0-1$ & 0.22 \\
\hline Mediterranean & 4 & $1-4$ & 2.82 & $2-4$ & 3.47 & $0-0$ & 0.00 & $0-0$ & 0.00 \\
\hline Caribbean & 4 & $0-0$ & 0.00 & $23-23$ & 23.00 & $1-1$ & 1.00 & $1-1$ & 1.00 \\
\hline
\end{tabular}


Table 5. Descriptive statistics and correlations (Dataset A)

\begin{tabular}{|c|c|c|c|c|c|c|c|c|c|c|}
\hline & Mean & SD & 1 & 2 & 3 & 4 & 5 & 6 & 7 & 8 \\
\hline $\begin{array}{l}1 \text { Perceived work } \\
\text { pressure }\end{array}$ & 3.312 & 1.387 & & & & & & & & \\
\hline 2 Deck & 0.634 & 0.483 & $0.238^{* * *}$ & & & & & & & \\
\hline 3 Engine & 0.281 & 0.450 & $-0.154 *$ & $0.823 * * *$ & & & & & & \\
\hline 4 Hierarchical level & 1.460 & 1.278 & $0.206^{* *}$ & -0.003 & 0.101 & & & & & \\
\hline 5 Night watches & 0.285 & 0.452 & 0.055 & $0.441 * * *$ & $-0.353 * * *$ & $-0.346 * * *$ & & & & \\
\hline $\begin{array}{l}6 \text { Ship's days at sea } \\
7 \text { Ship's arrivals and }\end{array}$ & 1.842 & 1.517 & $-0.304 * * *$ & 0.063 & -0.063 & 0.034 & 0.026 & & & \\
\hline departures & 11.527 & 5.295 & $0.302 * * *$ & -0.062 & 0.095 & -0.031 & 0.008 & $-0.871 * * *$ & & \\
\hline $\begin{array}{l}8 \text { Ship's days in port } \\
9 \text { Quality of social }\end{array}$ & 0.290 & 0.225 & -0.072 & -0.044 & 0.038 & 0.015 & -0.028 & -0.037 & $-0.206 * *$ & \\
\hline interactions & 5.804 & 1.025 & $-0.326 * * *$ & -0.072 & 0.101 & $0.179 * *$ & $-0.204 * *$ & $0.146^{*}$ & 0.058 & -0.097 \\
\hline
\end{tabular}

Notes: Means, standard deviations and correlations between variables (Level 1), based on 235 responses from time points 1 through 4 . Significance levels: ${ }^{\dagger} p<.1, * p<.05, * * p<.01, * * * p$ $<.001$.

Table 6. Descriptive statistics and correlations (Dataset B)

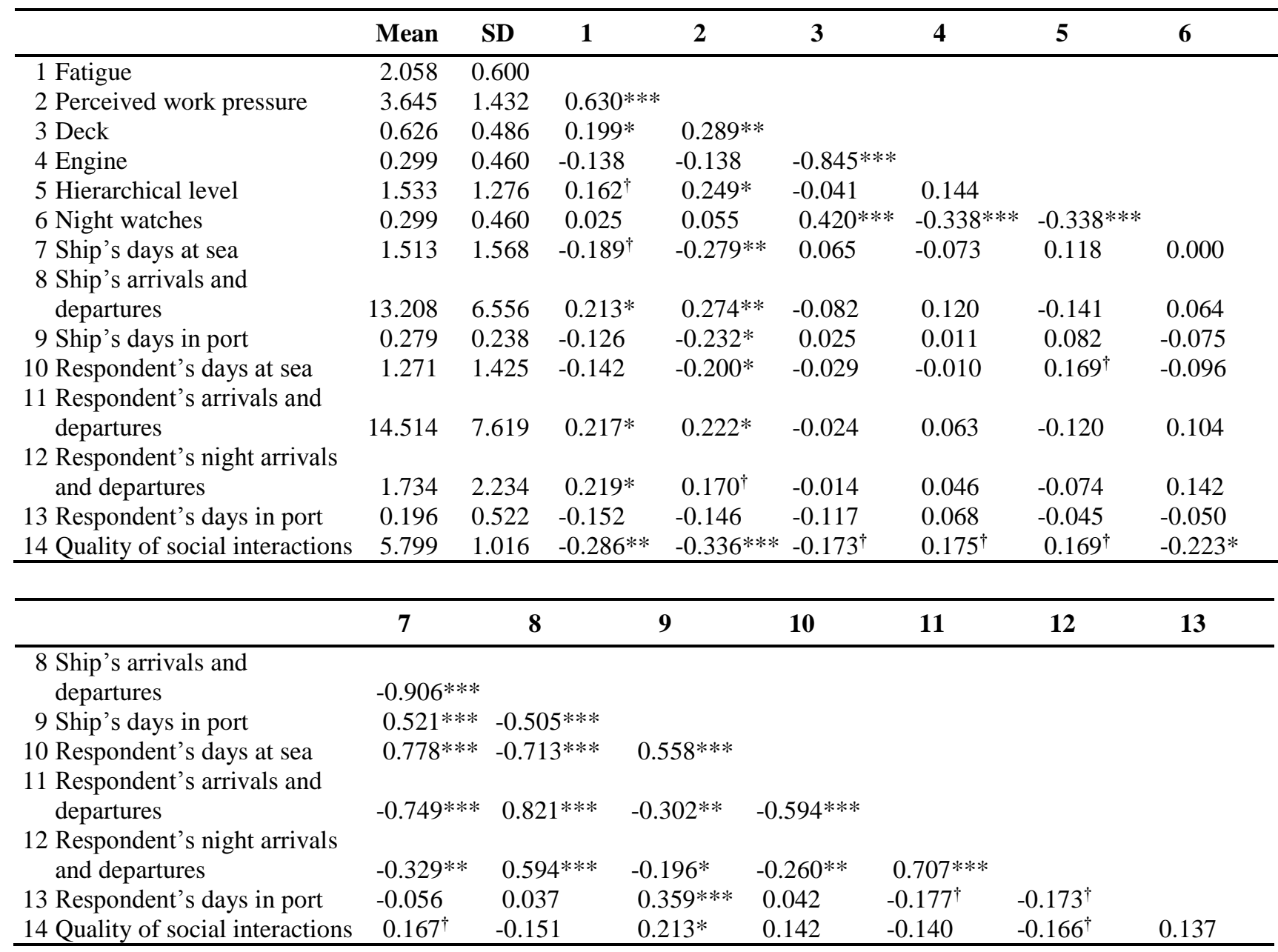

Notes: Means, standard deviations and correlations between variables (Level 1), based on 107 responses from time points 3 and 4 . Significance levels: ${ }^{\dagger} p<.1, * p<.05$, ** $p<.01$, *** $p<$ .001 . 
Table 7. Multilevel analyses with perceived work pressure and fatigue as dependent variables

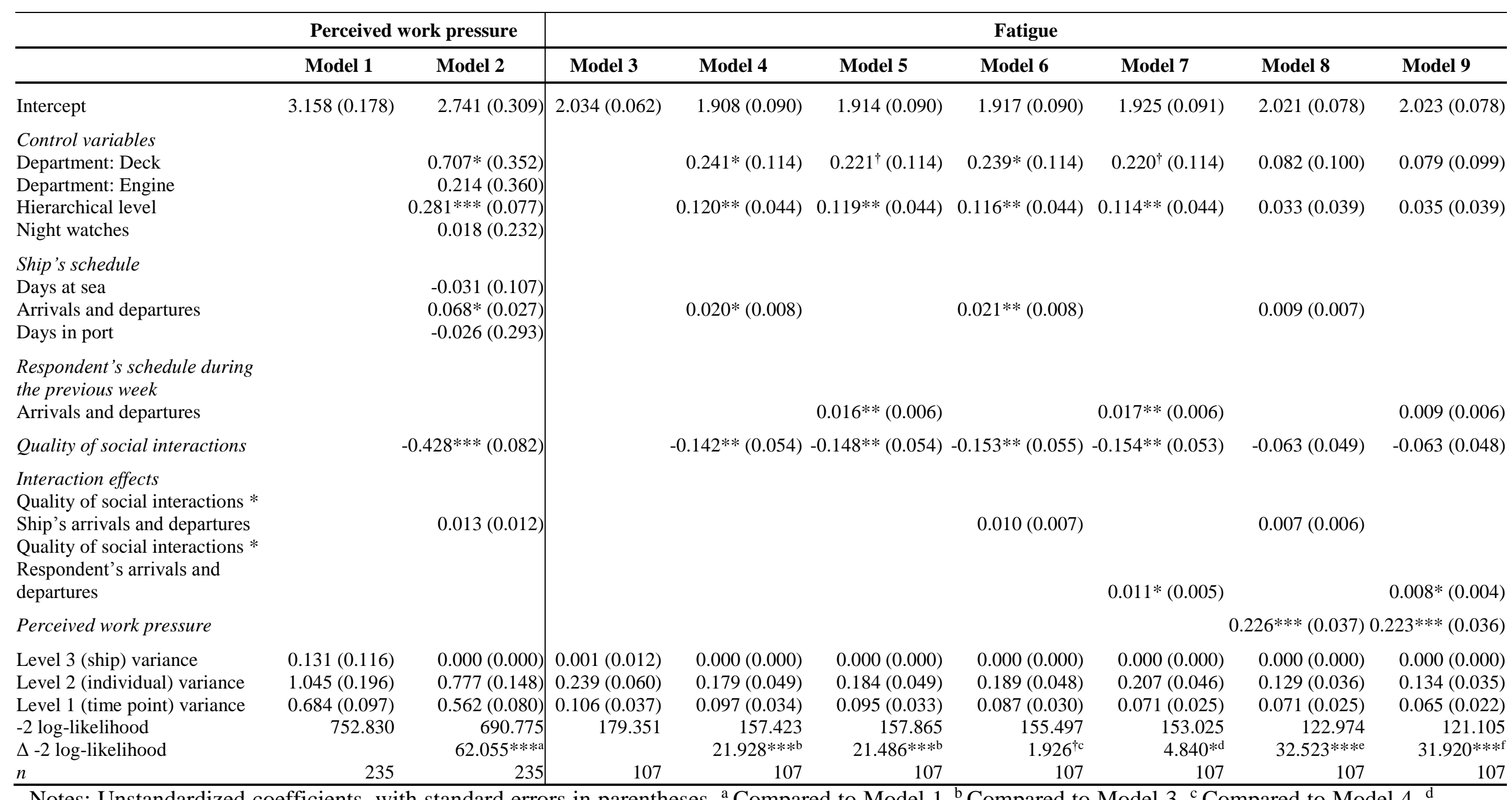

Notes: Unstandardized coefficients, with standard errors in parentheses. ${ }^{\mathrm{a}}$ Compared to Model $1 .{ }^{\mathrm{b}}$ Compared to Model $3 .{ }^{\mathrm{c}}$ Compared to Model $4 .{ }^{\mathrm{d}}$

Compared to Model 5. ${ }^{\mathrm{e}}$ Compared to Model 6. ${ }^{\mathrm{f}}$ Compared to Model 7. Significance levels: ${ }^{\dagger} p<.1, * p<.05, * * p<.01, * * * p<.001$. 
Figure 1. Theoretical model

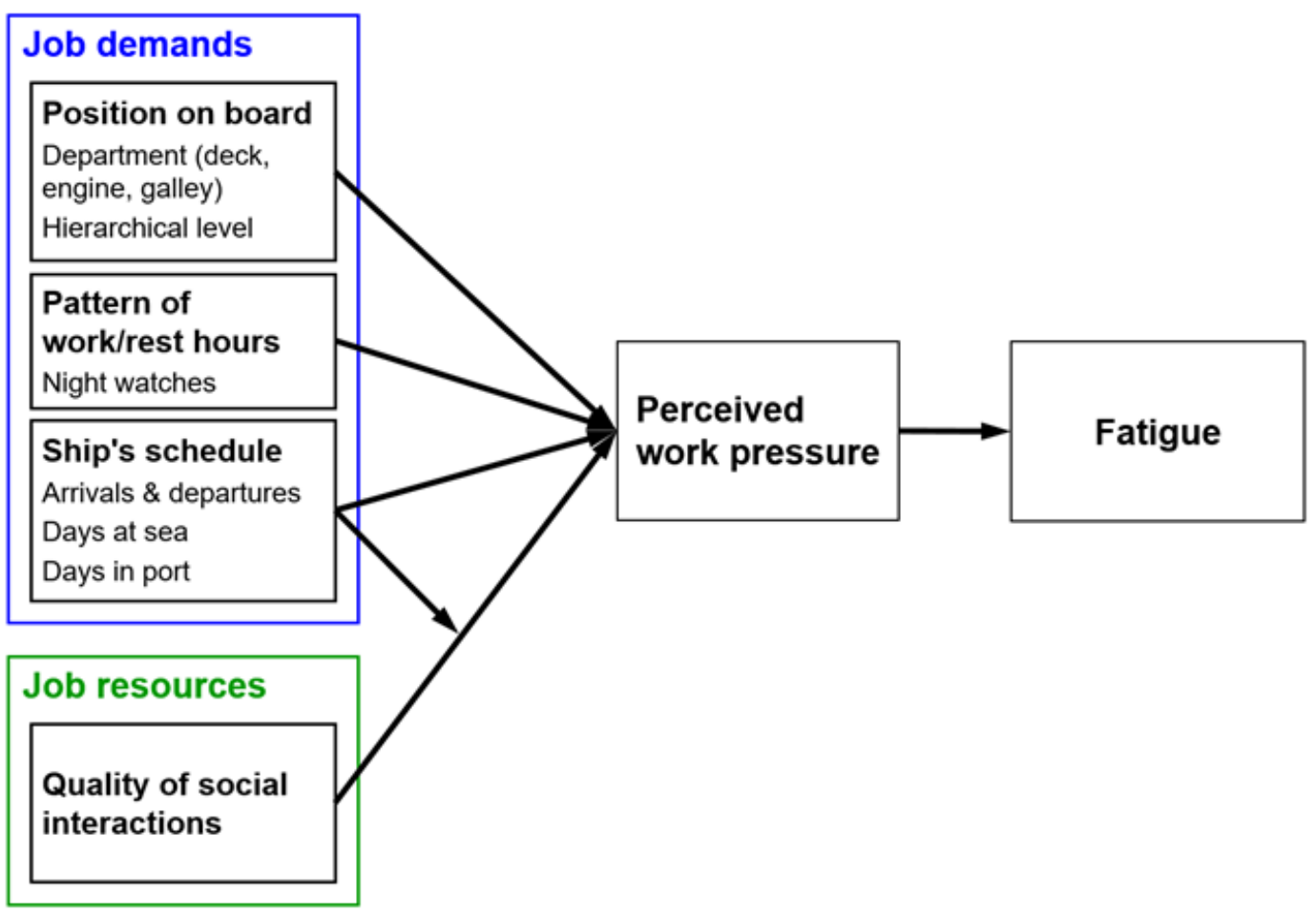

Figure 2. Fatigue and perceived work pressure: means by department.

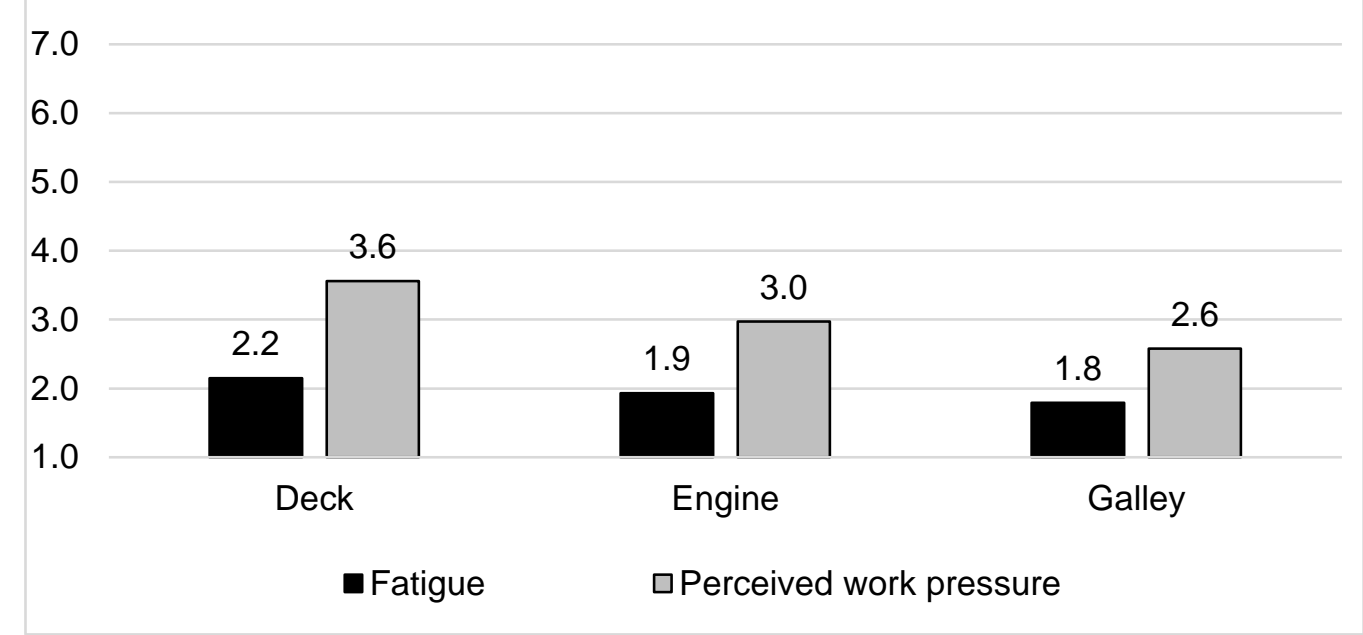


Figure 3. Effect of the interaction between respondents' number of arrivals and departures during the previous week and the quality of social interactions on fatigue.

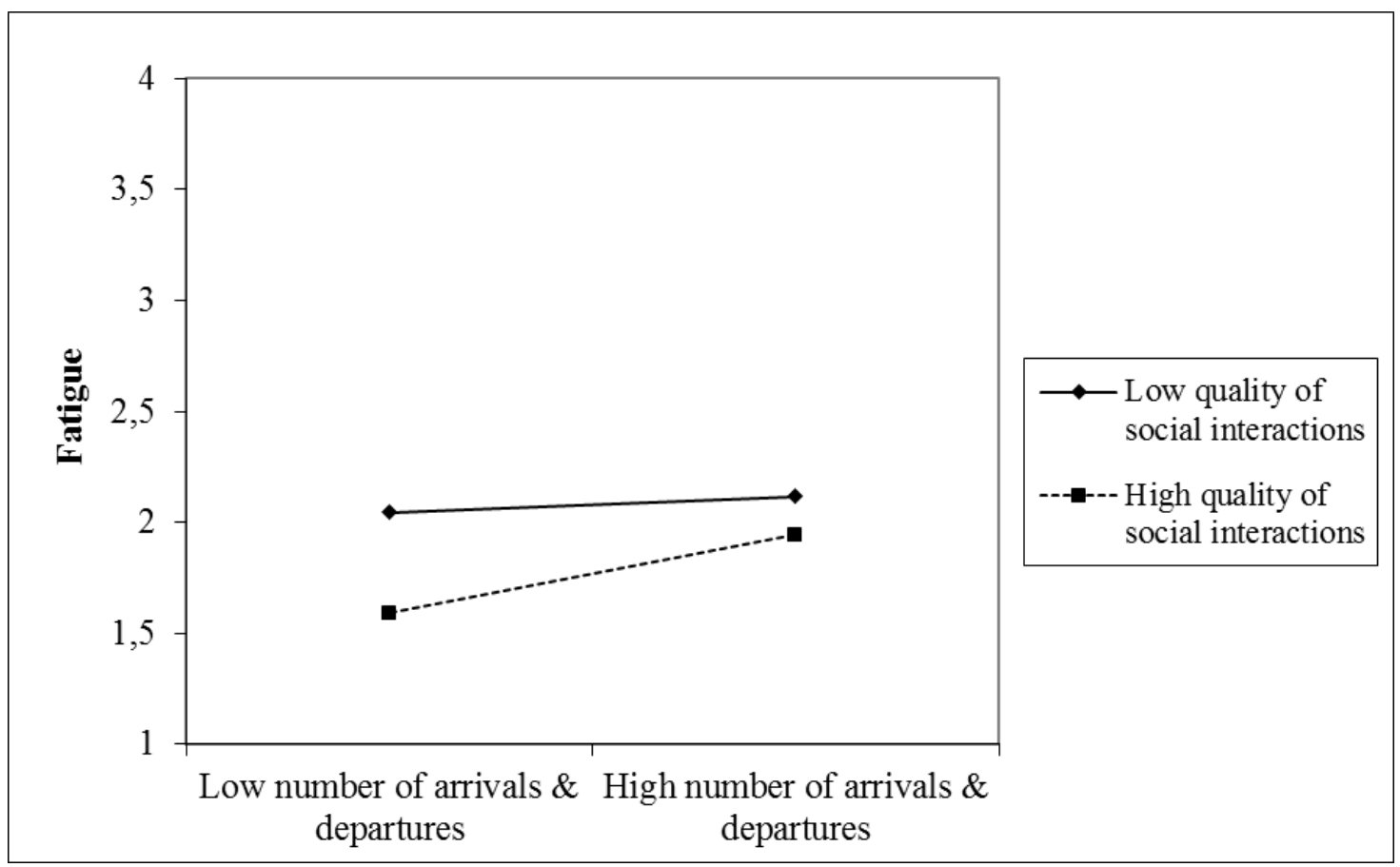

